\title{
La producción de cuerpos juveniles en el evangelismo pentecostal. Prácticas, discursos y agencia
}

\author{
The production of youth bodies in Pentecostal evangelism. \\ Practices, speeches and agency
}

Luciana Lago lucianalagocr@gmail.com

http://orcid.org/0000-0002-2546-1319

Instituto de Estudios Sociales y Políticos de la Patagonia; Universidad Nacional de la Patagonia San Juan Bosco (Argentina)

\section{Resumen}

Este artículo se centra en analizar cómo las creencias evangélicas producen y se inscriben en la corporalidad de los jóvenes, desde la idea nativa del "cuerpo como templo".

En el texto se presenta un recorrido por los estudios sociales del cuerpo como coordenadas teóricas desde las cuales indagar prácticas, discursos y el despliegue de la agencia juvenil respecto a las formas en que habitan sus cuerpos. Los datos presentados provienen del trabajo de campo etnográfico en distintas comunidades evangélicas, en especial: entrevistas, observaciones y registros respecto a la producción de corporalidades juveniles en estos espacios.

A través del análisis de las prácticas, discursos y concepciones sobre el cuerpo juvenil se presenta una mirada que apunta a reconocer las múltiples dimensiones que los atraviesan, las cuales incluyen tensiones relativas a la reproducción religiosa y la agencia, la regulación, el 
control, y disputas de sentido respecto a la relación con lo sagrado desde la vivencia de la creencia encarnada.

Palabras claves: corporalidad; jóvenes; agencia; pentecostalismo.

\section{Abstract}

This article focuses on analyzing how evangelical beliefs produce and are inscribed in the corporality of young people, from the native idea of the "body as a temple".

The text presents a journey through social studies of the body as theoretical coordinates from which to investigate practices, discourses and the deployment of the youth agency regarding the ways in which their bodies inhabit. The data presented come from ethnographic fieldwork in different evangelical communities, especially interviews, observations and records regarding the production of youthful corporalities in these spaces.

Through the analysis of practices, discourses and conceptions about the juvenile body, a view is presented that aim store cognize the multiple dimensions that cross them, which include tensions related to religious reproduction and agency, regulation, control, and disputes of meaning regarding the relationship with the sacred from the experience of the incarnated belief.

Keywords: corporality; young; pentecostalism; agency.

En Latinoamérica, especialmente en la última década, los estudios que desde las ciencias sociales se han ocupado del cuerpo se han multiplicado y diversificado significativamente. A grandes rasgos, es posible concentrar las diferentes perspectivas de abordaje de la corporalidad en dos grandes grupos. Por un lado, encontramos investigaciones que conciben al cuerpo como un objeto sobre el cual el colectivo impone representaciones simbólicas y prácticas disciplinares. Por otro, contamos con aproximaciones que toman como punto de partida la experiencia corporal de los actores y que destacan el papel activo de la corporalidad en la constitución del entramado social. Revisando estas miradas encontramos que las perspectivas propuestas no son excluyentes sino complementarias. $\mathrm{Y}$ que son justamente las religiones y creencias ámbitos particularmente ilustrativos de esta complementariedad, ya que si bien los sistemas rituales, los dogmas y los discursos le son impuestos al individuo, éste al encarnarlos los reactualiza y muchas veces los transforma. 
En este sentido, el objetivo de este trabajo es explorar esta complementariedad; en particular, me interesa atender a las formas en que el cuerpo juvenil es objeto de representaciones y prácticas disciplinares en el ámbito de las comunidades evangélicas pentecostales, desde la idea nativa del "cuerpo como templo". Busco entonces indagar cómo los cuerpos juveniles producen sentido, a la vez que los cuerpos juveniles están inscriptos en tramas de significación que proyectan regulaciones, deberes y formas de vivenciar el cuerpo. Parto de la idea central que el cuerpo no es sólo algo sobre lo que se actúa sino que también es productor de acción, que llevado al caso evangélico lleva a comprender el cuerpo no como un mero receptáculo de lo sagrado, o como un simple reflejo de este, sino más bien un elemento fundamental para comprender el universo religioso evangélico en una perspectiva juvenil.

Como punto de partida, presento un breve recorrido por el estudio del cuerpo en las Ciencias Sociales con la intención de dar cuenta de las coordenadas teóricas que guían este trabajo, para luego sí centrarme en el análisis de situaciones y datos surgidos del trabajo etnográfico con un grupo de jóvenes integrantes de iglesias evangélicas pentecostales.

\section{Coordenadas teóricas: el cuerpo como campo de estudio en las Ciencias Sociales}

Distintos trabajos que presentan una genealogía sobre los estudios sociales del cuerpo parten de reconocer y criticar la influencia de la concepción moderna de los cuerpos, originada en el dualismo cartesiano, y el modo en que este proceso modernizador fue ponderando la racionalidad, la productividad, la disciplina y arrinconando lo corporal (1). Este proceso en sí ponderaba a la razón poniéndola en inevitable lucha contra el cuerpo, y siendo que el cuerpo se halla escindido de la razón, no generaba interés su estudio social. Siguiendo la genealogía y revisión hecha por Citro $(2009 ; 2011)$ el estudio antropológico de la corporalidad recién comienza a delinearse como un campo específico de estudio en la década de 1970. Como plantea esta autora, si el cuerpo fue considerado un mero objeto de la naturaleza a domesticar, la antropología resaltará su construcción sociocultural, analizando cómo cada grupo construye y utiliza de manera particular los gestos, las técnicas corporales de la vida cotidiana y de los trabajos, así como sus cuerpos en las manifestaciones artísticas y rituales.

Igualmente junto a los aportes de la antropología, una relectura de autores clásicos de la sociología ya da cuenta de un primer interés en el lugar del cuerpo en el juego de las relaciones sociales. Así, puede reconocerse en los estudios de Marx una mirada sobre la sociedad industrial moderna y de cómo el modo de producción capitalista produjo una 
reorientación en las relaciones del sujeto y su cuerpo a partir de la idea del cuerpo máquina. Así, el trabajo productivo en las condiciones del capitalismo industrial se ligaba a connotaciones ligadas al sacrificio, a la productividad y al rendimiento, y necesitaba una herramienta útil que era el cuerpo. De esta forma se reconoce al cuerpo-máquina como engranaje de la producción; y la fuerza del trabajador, su energía y resistencia pasan a ser objetos de explotación capitalista al servicio de la expansión del capital. Así, Marx ubica al cuerpo del trabajador como el material de explotación, dominación y sujeción por parte de la burguesía y del capital (1976: 112).

El trabajo de Elías (1993) sobre el proceso civilizatorio en la Europa occidental es importante en este recorrido, dado que hizo foco en que el cuerpo tiene una historia. Elías señaló, en particular, que las formas en que nuestra comprensión y nuestras experiencias modernas sobre el cuerpo son históricamente específicas y surgen de procesos sociales y psicológicos que se remontan al siglo XVI, etapa en que el "proceso civilizatorio" se caracterizó por modificar los grados de tolerancia en lo relativo al pudor y los límites de la vergüenza íntimamente relacionados con la corporalidad. Otro autor de referencia es Marcel Mauss, quien ocupa un lugar pionero en el análisis socio antropológico del cuerpo con su trabajo sobre las técnicas corporales (1936), donde propone la idea que no hay un comportamiento natural en relación al cuerpo y que convertirse en un individuo social implica un determinado aprendizaje corporal. Plantea el concepto de técnicas corporales entendidas como "las maneras por las cuales los hombres, de sociedad a sociedad, de una forma tradicional, saben servirse de su cuerpo" (Mauss, 1974: 401) y que estas técnicas se producen a partir del aprendizaje compartido con otros en el marco de distintas relaciones sociales.

Siguiendo este recorrido, encontramos en las obras de Mary Douglas (1966; 1988) ideas relevantes para atender a las formas en que la cultura opera sobre el cuerpo. En sus trabajos el cuerpo se considera como un sistema de clasificación primario para las culturas, medio a través del cual se representan y se manejan los conceptos de orden y desorden. Douglas plantea que existen dos cuerpos, el "cuerpo físico" y el "cuerpo social", y afirma que "el cuerpo social restringe el modo en que se percibe el cuerpo físico" (Douglas, 1988: 93). Visto así el cuerpo es un medio, puesto que está mediatizado por la cultura que lo ciñe a actuar de formas concretas, haciendo que la situación social se imponga en el cuerpo.

Otra obra de referencia de esta autora es Pureza y peligro (1966) donde plantea que la división entre lo sagrado y lo sucio impacta en la vida cotidiana de los individuos, analizando las leyes bíblicas del Levítico y en particular las prohibiciones ligadas a los alimentos. Rescato esta mirada sobre la relación cuerpo, consumos y religiones dado que es útil para analizar una 
práctica religiosa ligada al control del cuerpo como es el ayuno y la castidad, en especial donde emerge la idea sobre la impureza como un peligro que afecta la relación con la divinidad, desde la idea cristiana del cuerpo como templo que desarrollo luego.

Las obras de Foucault (1991; 1992; 1997; 2003; 2008), son una referencia ineludible para comprender cómo lo corporal fue procesado socialmente en distintas etapas, en particular con la irrupción de las sociedades disciplinarias y la formación de saberes específicos ligados al cuerpo, que a su vez conservan elementos provenientes del campo de lo religioso combinados en un saber-poder. Foucault plantea que la innovación de las técnicas disciplinarias y sus tecnologías de poder se centran en fabricar un cuerpo a la vez útil y sometido, un cuerpo dócil, y que la creación de estos cuerpos se produce a partir de la combinación entre la vigilancia jerárquica y la sanción normalizadora. De esta forma los dispositivos y las tecnologías de la sociedad disciplinaria definen al cuerpo como un producto social, insertado en relaciones de poder y dominación y para docilitar al cuerpo se recurre a mecanismos estratégicos, prácticas discursivas, disciplinas e instituciones. Existe una complementariedad entre un abordaje foucaultiano dedicado a examinar cómo las tecnologías del poder actúan sobre los individuos (Foucault, 1991) y su abordaje posterior dedicado a indagar los modos en que las tecnologías del yo actúan sobre los individuos desde su interior, permitiendo su constitución como sujetos (2008). Esta última perspectiva nos ofrece elementos para comprender las relaciones entre los poderes sobre el cuerpo y cómo los propios individuos actúan sobre su propio cuerpo desde la idea del "cuidado de sí mismo". Esto se observa en particular en el caso de los controles sobre los cuerpos juveniles evangélicos, en especial lo vinculado al control de la sexualidad y los consumos del cuerpo centrados en la idea del cuerpo-templo.

Las críticas extendidas a Foucault por su postura como postestructuralista, se centran en remarcar que su explicación del cuerpo procesado socialmente deja escaso lugar para comprender cómo los individuos adoptan y traducen los discursos disciplinantes que lo atraviesan. En este punto considero que la noción de tecnologías del yo propuesta por Foucault salva en parte estas críticas, pues plantea que se puede atender a un conjunto de técnicas y procedimientos mediante los cuales los propios individuos operan en sus cuerpos a fin de corregirse y en el léxico pentecostal, mantenerse en santidad. Sobre este punto en especial me voy a detener cuando me refiera en el próximo apartado a la construcción de cuerpos juveniles dóciles, en el marco del pentecostalismo, analizando situaciones donde los jóvenes operan sobre sí mismos dando cuenta de particulares formas de gestión de sus cuerpos.

Otra perspectiva de análisis sobre corporalidades es la propuesta de Thomas Csordas, la cual proviene de un enfoque fenomenológico que recupera la perspectiva filosófica de Merleau 
Ponty sobre el ser-en-el-cuerpo. Csordas piensa al cuerpo no sólo como un objeto "bueno para pensar", sino como "necesario para ser" (2011: 83). Desde este enfoque se postula la necesidad de atender a la experiencia corporizada, buscando comprender lo que el cuerpo hace, partiendo de que el cuerpo no es sólo algo sobre lo que se actúa sino que también es productor de acción. Para dar cuenta de los procesos en que las identidades se corporalizan, Csordas desarrolla la perspectiva del embodiment definida como "una aproximación fenomenológica en la que el cuerpo vivido es un punto de partida metodológico, antes que un objeto de estudio, un campo indeterminado definido por la experiencia perceptual y por los modos de presencia y compromiso en el mundo" (2011: 51). De esta forma, Csordas busca superar la idea que lo social se inscribe en el cuerpo para hablar de lo corporal como auténtico campo de la cultura, subrayando su dimensión potencial, intencional, intersubjetiva, activa y relacional.

Csordas encuentra que el cuerpo desempeña un papel más importante en el fenómeno de la atención del que tradicionalmente se le ha atribuido (dada la hegemonía de perspectivas de cuño intelectualista en este campo); por ello considera relevante reconocer los procesos en los cuales prestamos atención y objetivamos nuestros cuerpos a partir del término modos somáticos de atención. Señala que los modos somáticos de atención "son modos culturalmente elaborados de atender a y con nuestro cuerpo al entorno que incluye la presencia encarnada de otros" (2011: 87). Así, atender "con" y atender "a" el cuerpo no son procesos separados sino que en cierta medida se producen a la vez, debido a nuestra naturaleza encarnada y al medio intersubjetivo que habitamos. En esta perspectiva cobra valor sobre todo profundizar cómo los modos somáticos son in-corporados, aprendidos y compartidos con otros. Al respecto plantea Rabelo (2014) en su estudio sobre los cuerpos en el candombe, que el concepto de modos somáticos de atención para el campo de los estudios religiosos resulta valioso en tanto permite convertir en objeto de investigación toda una serie de experiencias religiosas que en otras formulaciones tendían a ser agrupadas en categorías generales, o en algunos casos hasta despectivas bajo la idea de "estados alterados de conciencia" (2014: 236).

Esta mirada nos resulta interesante para analizar la concepción evangélica del cuerpo como templo-cuerpo territorio, que así como es el asiento de lo sagrado puede ser receptáculo de algún tipo de entidad que toma o posee los cuerpos, generando distintos tipos de males. Este último punto lo conocí en particular con casos en que se planteaba una guerra espiritual para liberar cuerpos jóvenes habitados por demonios de muerte, maldad y sobre todo "vicios". En el próximo apartado me detengo en desarrollar la idea de cuerpo territorio y cuerpo templo el cual articula el eje de este trabajo. 


\section{Cuerpo templo-cuerpo territorio}

Cuando me refiero a la noción de cuerpo-territorio resulta clave partir de la idea que el cuerpo se hace territorio en el sentido social de su construcción, y que en esta construcción se cruzan discursos, normas y prácticas que pueden dar lugar a disputas. En este punto es importante reconocer la influencia de la teoría feminista desde la cual se construye la idea de cuerpo territorio en un sentido político, referido a considerar los cuerpos femeninos como territorios de disputa, reflexionando críticamente sobre los controles y regulaciones sobre los cuerpos de las mujeres. Una de las autoras que ha explorado la noción de cuerpo territorio es Rita Segato, en su análisis sobre las formas de violencia que se ejercen sobre los cuerpos femeninos como formas de pedagogía social en el caso de Ciudad Juárez (2) (Segato, 2013). De esta perspectiva me interesa destacar la mirada de los cuerpos como territorios vivenciados, que dan cuenta de experiencias donde lo social se inscribe en el cuerpo, por lo que cobra valor recuperar no solo lo que se hace con el cuerpo, sino el conjunto de marcos normativos que suponen disciplinamientos y rupturas.

Llevado al campo de lo religioso, y en relación a la idea del cuerpo como templo, se encuentra una idea extendida sobre la relación cuerpo y pecado, que remite a una mirada que divide a la persona en cuerpo y alma, priorizando el alma o el espíritu sobre el cuerpo o la carne. Desde esta visión, el cuerpo es parte de la existencia terrenal y es el lugar de las tentaciones siempre en permanente posibilidad de caer en pecados. Por ello el desafío -sobre todo para los jóvenes- es mantenerse en un estado de pureza o santidad que debe lograrse a pesar o en contra del cuerpo. Para profundizar esta mirada, recuperamos los aportes de la geografía cultural religiosa en la línea esbozada por Carballo desde la cual se plantea que:

\footnotetext{
la corporalidad adquiere relevancia a la hora de interpretar las prácticas y creencias religiosas que toman como símbolo y objeto al cuerpo, es decir como una escala territorial apropiada. (...) Así es posible analizar el cuerpo y su imagen en tanto vehículo de disciplinamiento social-religioso, pero a la vez como locus donde es posible reinventar las identidades y, a la vez, ofrecer espacios de individualización con lo divino o sagrado desde la experiencia directa (Carballo, 2012: 70).
}

En la experiencia evangélica el cuerpo posee una gran centralidad, es el templo vivo donde los evangélicos entienden que se manifiesta la gracia del Espíritu Santo, la cual se expresa en sus 
dones y carismas como son el poder de hablar en lenguas divinas, la sanación del cuerpo y el espíritu, las visiones proféticas, el entendimiento, el talento para "ministrar" a través de la música como un don, entre otros usos. En especial, se considera que el cuerpo es el espacio donde la presencia del Espíritu Santo (dones y carismas) "desciende" corporalizándose, de la misma forma también el cuerpo puede ser "tomado" por la presencia de demonios (a los que puede expulsarse a través de complejos rituales de "liberación). Así, la concepción subjetiva del cuerpo como vehículo del alma y el espíritu, vincula las experiencias corporales tanto de salud como de malestar o enfermedad, con aspectos relacionados al mundo espiritual, ya sea por la relación con Dios y el Espíritu Santo, o bien por la influencia de espíritus malignos que perturban y afectan el cuerpo.

Desde la mirada evangélica, se considera que el cuerpo es el receptáculo privilegiado de lo sagrado -un "templo de Dios"- y constituye por lo tanto el objeto sobre el que recae la disciplina espiritual, sobre todo desde los mandatos tradicionales que plantean que el cuerpo no es propio, sino que se lo habita en espíritu pero los cristianos se lo deben a Dios y su uso debe estar regido por los principios bíblicos. Desde la perspectiva evangélica-pentecostal el cuerpo juvenil en particular es un espacio de regulación y control, con especial atención en el ejercicio de la sexualidad, el consumo de pornografía, y al control y prohibición sobre determinados consumos como las drogas. Encuentro que subyace una visión del cuerpo como la carne, que de por sí se la considera pecaminosa, débil, tentada constantemente por el demonio, por lo cual el desafío para los jóvenes cristianos es "vencer a la carne", domesticarla. Esta idea de santidad se cruza estrechamente con la producción de un tipo de cuerpos legítimos y de los que no lo son. En este sentido, dentro del universo evangélico es clara la construcción de modos diferenciados de ser y de estar en el mundo correspondientes a mujeres y varones, en particular desde el mandato de la heterosexualidad como la única vía natural y posible para experimentar el cuerpo y sus deseos. Se parte de considerar que los sexos son el masculino y el femenino tal cual son definidos por la biología y sobre todo por "el acto de la creación divina", por ello las constantes prédicas orientadas a prevenir los posibles "desvíos" de la moral sexual cristiana. Como ha explorado Mosqueira (2014) se promueve en el evangelismo pentecostal una ética de la santidad relacionada principalmente con las restricciones sexuales, donde lo que se intenta es reservar al joven en cuerpo, alma y espíritu, pues "debido a su condición liminal la juventud es pensada en constante guerra espiritual en combate continuo entre el espíritu y la carne, entre lo sagrado y lo profano, entre lo puro y lo impuro, entre la santidad y la mancilla" (2014: 213). 
A su vez, en relación con la producción de cuerpos legítimos observamos que el cuerpo, su "uso e imagen" genera diferencias, límites y fronteras entre jóvenes y adultos, sobre todo, si se considera que el cuerpo y la edad son los primeros criterios de diferenciación entre los jóvenes y los que no lo son. Desde esta mirada es posible reconocer que los cuerpos juveniles se encuentran tensionados entre la normalización y la personalización, la reproducción y la agencia, los procesos de disciplina y el empoderamiento, dando cuenta tanto de las sutiles formas de ejercicio del poder como de las posibilidades de agencia que los sujetos viven en sus prácticas cotidianas, particularmente en sus corporalidades (Citro, 2011: 54). Siguiendo a esta autora, entiendo que analizar las corporalidades requiere mirar las in-disciplinas en los cuerpos juveniles, entender los diversos modos de "hacer corporalmente" como instancias productivas de sentidos. Es por ello que los cuerpos juveniles no pueden entenderse como meros objetos que soportan pasivamente aquellas prácticas y representaciones culturales que los buscan modelar, sino que también incluye una dimensión productora de sentidos, con un papel activo y transformador en las comunidades evangélicas a las que pertenecen.

Este último punto se vincula con la cuestión de la capacidad de agenciamiento y las relaciones entre lo normativo y las experiencias concretas de los sujetos. En relación a la agencia, inspirada en los escritos de De Certeau (1996), me interesa indagar los artificios para gestionar opciones cotidianas, en donde podemos dirigir la atención a la agencia de los sujetos para dar cuenta -sin desconocer la existencia de mecanismos de control- del modo en que, mediante distintas maneras de hacer, distintas tácticas o performances, los jóvenes pueden apropiarse de sus cuerpos para disputar e imaginar otras experiencias posibles. Para complejizar esta mirada, recupero el planteo de Mahmood (2006) que al abordar prácticas religiosas remarca que es clave poner en discusión las nociones liberales de libertad y autonomía que guían muchas concepciones sobre el agenciamiento, dado que la capacidad de agencia no es solo resistencia en oposición a la represión, sino que la agencia puede producirse dentro mismo de las normas, debido a que estas pueden ser "performadas, habitadas y experienciadas de varias maneras" (2006: 136), y no sólo consolidadas o subvertidas. De esta forma, la agencia puede estar en el modo en que una determinada norma es acatada, en cómo es vivida y experimentada.

Pero así como el cuerpo puede ser la fuente del pecado, también es clave para la experimentación de lo sagrado, ya que el cuerpo permite la conexión con lo espiritual, la experiencia individualizada con lo divino, es decir, el cuerpo puede ser fuente de virtud y puente con lo sagrado. Visto de esta forma, entendemos que es posible analizar el cuerpo y su 
imagen en tanto espacio de disciplinamiento y regulaciones sociales y religiosas, pero a la vez como locus donde es posible experimentar, "sentir" la creencia.

Desde estas bases propongo una mirada que parte de analizar las prácticas para encontrar cómo se están produciendo y articulando sentidos sobre el cuerpo juvenil cristiano como un territorio. Me interesa partir del análisis de las prácticas para examinar el cuerpo que de ahí emerge, pues considero que mantener el análisis anclado en las prácticas permite comprender las particularidades de la situación y la singularidad de los eventos en que los cuerpos son producidos socialmente. En un sentido similar, busco pensar lo nuevo en lo viejo, es decir, entiendo que las practicas que realizan los jóvenes con quienes me vincule en el trabajo de campo no son plena novedad, sino que implican continuidades y desplazamientos con respecto a prácticas ligadas a formas ascéticas más tradicionales, como lo es por ejemplo el ayuno y las formas de castidad que presentaré a continuación.

\section{La construcción de cuerpos dóciles evangélicos en perspectiva juvenil}

En este apartado voy a centrarme en analizar lo que llamo la producción de cuerpos dóciles en el evangelismo pentecostal. Recupero la perspectiva foucaultiana para analizar las formas de ascetismo cristiano, considerando las restricciones sobre el ejercicio de la sexualidad como casos desde los cuales es posible comprender las formas particulares de gestión de la corporalidad juvenil en el pentecostalismo.

A lo largo de mi trabajo de campo de modo extendido encontré, en los discursos de pastores y líderes, la idea que los jóvenes son un sector clave para sostener y continuar sus obras religiosas, por lo que el desafío es encauzar la energía juvenil hacia el desarrollo de tareas evangelísticas, desde el principio articulador de lograr "aplacar la carne" y mantener el cuerpo como un territorio puro. En este sentido, para que los jóvenes se sostengan en este estado de pureza, resulta clave practicar los "cuidados de sí", es decir mantener una conducta centrada en el autocontrol de los cuerpos y sus deseos. Sostengo que estas conductas pueden ser comprendidas como tecnologías del yo, las cuales se ligan a los procedimientos, técnicas y ejercicios mediante los cuales el sujeto se ve "llamado a tomarse a sí mismo como objeto de conocimiento y campo de acción, a fin de transformarse, de corregirse, de purificarse" (Foucault, 1991: 41). Estas tecnologías 
permiten a los individuos efectuar un cierto número de operaciones en sus propios cuerpos, en sus almas, en sus pensamientos, en sus conductas, y ello de un modo tal que los transforme a sí mismos, que los modifique, con el fin de alcanzar un cierto estado de perfección, o de felicidad, o de pureza, o de poder sobrenatural (1991: 48).

Estas nociones me interesan en particular, para analizar los modos en que se vinculan las tecnologías del yo con las prácticas de ascetismo y los controles sobre los cuerpos juveniles en el marco del pentecostalismo, considerando datos y situaciones que registre a lo largo del trabajo de campo. Al respecto una práctica extendida es, por ejemplo, mantenerse en ayuno como forma de purificarse y alcanzar un estado de mayor sensibilidad espiritual, acompañado de oración y llamados a silencio. Visto así el ayuno como práctica religiosa propia del ascetismo cristiano, puede ser pensada como un tipo de tecnología del yo en dos sentidos: es un ejemplo claro de las formas de la agencia en que se puede performar una norma para dar cuenta del control corporal desde el cual se busca proyectar una imagen del creyente en este caso como un "joven comprometido", expresando así su pertenencia a la comunidad espiritual. $Y$ a la vez, en términos subjetivos y recuperando los relatos los jóvenes ayunantes, ellos sostienen que a través del trabajo pastoral combinado con la oración logran una experiencia con lo sagrado de gran intensidad.

Si bien el ayuno y las prácticas devocionales intensivas son unas formas en que se expresa la gestión de la corporalidad, el control del ejercicio de la sexualidad juvenil es el campo por excelencia donde se busca producir un tipo de cuerpo dócil y donde también se despliegan las indisciplinas. Al respecto, quisiera retomar una anécdota de campo que a los fines analíticos de este apartado resulta sumamente rica por el tipo de conflicto desatado donde se cruzan nociones de corporalidad, música, normas y prohibiciones.

El caso en cuestión se trata de una situación que se produjo con Miguel, un joven músico que integraba el grupo de adoración de una de las iglesias en las que desarrollé trabajo de campo. Noté que Miguel, si bien asistió a las reuniones durante un mes aproximadamente, fue reemplazado de su rol de guitarrista en el grupo de adoración. Gracias a cierta confianza y familiaridad que fui logrando a través del tiempo compartido, le pregunté cuál era el motivo por el cual no estaba participando, a lo cual me respondió que no podía tocar en el grupo de adoración porque había sido "apartado" por el pastor, debido a una falta que había cometido. Indagando supe que Miguel llevaba unos meses saliendo con una joven que no es cristiana, y en una ocasión mantuvo relaciones sexuales con ella. Pasados unos días, su "conciencia" hizo que se lo contara al pastor sabiendo que había cometido una falta grave. Como consecuencia 
de este hecho, el pastor lo amonestó retirándolo del grupo de adoración durante un período de tiempo, ya que consideraba que por su falta Miguel no se hallaba en el estado de pureza y santidad que se espera de quien debe ministrar con la música. Con su falta al mandato de castidad lo que Miguel habría roto es ese pacto de comunión con Dios, arriesgando la posición privilegiada que tenía al integrar el grupo de adoración. Así, en su caso "la carne" le había ganado al espíritu, aunque luego sintió el arrepentimiento por lo que confesó esta situación al pastor y aceptó el castigo.

Para el análisis de esta situación de campo recuperó la perspectiva foucaultiana referida al control de la sexualidad y las tecnologías del yo y su relación con la confesión y el castigo. Como plantea Foucault:

\begin{abstract}
Existe una diferencia significativa entre las prohibiciones sobre la sexualidad y las demás prohibiciones. A diferencia de lo que ocurre con otras prohibiciones, las prohibiciones sexuales están íntimamente relacionadas con la obligación de decir la verdad sobre sí mismo (...). La conducta sexual más que cualquier otra se somete a reglas muy estrictas de secreto, decencia y modestia, de tal modo que la sexualidad se relaciona de una forma compleja y extraña, a la vez con la prohibición verbal y con la obligación de decir la verdad, así como con el hecho de esconder lo que se hace y con el descifrar lo que uno es (1991: 45-46).
\end{abstract}

En esta línea sostiene que la sexualidad "no es lo que estamos obligados a callar, es lo que estamos obligados a confesar" (2008: 159). Dentro de las formas de sanción, Foucault destaca la confesión como forma de poder disciplinario, dado que a través de la confesión el sujeto habla de sí mismo, se produce así una vigilancia interna que luego se brinda a las autoridades que interpretan ese discurso para luego instaurar el castigo.

La confesión entonces es una forma de poder que se ejerce sobre los individuos para que puedan indagarse, explorarse, para luego descubrirse ante otro superior. Hay un régimen para presentarse ante una autoridad y que esta juzgue la falta y defina el castigo con el que puede repararse el error cometido. En el caso que presenté, una cuestión que me interesa resaltar es que desde la mirada cristiana el ejercicio de la sexualidad que realizó Miguel no se trata de un acto privado, sino que es una falta que se aborda de modo relacional, su acción no sólo incide en su vida y en la de su novia sino que afecta al grupo en su conjunto, pues uno de sus aspirantes a ser ministro musical se "desvió" y estaría "contaminado" por lo cual debe ser apartado de sus compañeros. A su vez, en el caso de su novia cobra peso la imagen construida sobre la mujer como "amenaza de la carne" (Citro, 2009: 311) quien tienta y 
consiente para que se deje librado el deseo de "la carne", lo cual en la visión evangélica se produce por sostener un noviazgo con una joven que no es cristiana.

Es interesante además considerar el acto de la confesión y la situación por la cual Miguel da cuentas ante el pastor quien como figura de autoridad se dedica a la escucha, el análisis y sobre todo la corrección y orientación del penitente, en especial en casos como este donde lo que emerge claramente es que se trata de una infracción sexual ligada a no cumplir con la sexualidad legítima. A su vez, si pensamos en la sanción aplicada, encontramos que en este caso se buscó adecuar la penitencia ajustándola en particular a la función o el lugar que tenía el joven en el grupo religioso. Una vez que Miguel develó la verdad sobre su infracción se supo que su cuerpo no se hallaba en santidad, sino que el mismo estaba contaminado y es por ello que se consideró que en esta condición no puede tocar la guitarra, pues no se puede entrar en comunión con Dios cuando el cuerpo no está en un estado de pureza.

Estas formas de regulación y de autovigilancia se condensan en el extendido consejo de "huir de las pasiones juveniles", considerando que la juventud como etapa del ciclo vital es un momento donde las pasiones desbordan al joven afectándolo en sus decisiones y generando consecuencias en su vida. Así, se insta a los jóvenes al autogobierno de sus cuerpos ejercido con convencimiento y compromiso sobre la idea de "guardarse" para el matrimonio, priorizando el espíritu sobre la carne, promoviendo la práctica de una espiritualidad intensa para mantenerse en ese estado de santidad y castidad. A la vez, es clara la forma en que se insiste en el autocontrol de los cuerpos siguiendo los valores morales cristianos en los que se destaca un esfuerzo por definir, regular y controlar unas formas correctas de sexualidad que tienen a la heterosexualidad como única alternativa posible. Así, desde el principio de "dominar el cuerpo para controlar la carne" se construyen maneras adecuadas e inadecuadas de tener un género, donde los estilos corporales y eróticos permitidos y prohibidos plantean una coherencia normativa entre sexo, género y deseo.

Si bien se plantea una idea de libertad cristiana sostenida en el principio que "todo me es lícito pero no todo me conviene", esta postura también da lugar a complejas articulaciones subjetivas sobre lo que puede o no ser perjudicial para cada joven. En el caso de Miguel, es notable que él interpretó su conducta como perjudicial para sí mismo y por ello consideró que debía confesar y aceptar el castigo. Sin embargo, informalmente pude saber de casos de otros jóvenes quienes no acuerdan con el principio de la castidad obligatoria, planteando que no hay perjuicio personal en contar con experiencias sexuales por fuera del matrimonio, y que "luego rendirán cuentas". A su vez, y con el poder disruptor que puede tener el humor en estos temas, se recupera el dicho popular inspirado en la biblia que se refiere a que "el que esté libre de 
pecado que tire la primera piedra", dando la idea que la castidad propuesta como principio es un ideal difícil de lograr, y a la vez se trata de un acto privado por lo que critican sobre todo la actitud de vigilancia y juzgamiento de las vidas ajenas. En el mismo sentido, también encuentran que es excesiva la exhortación a los jóvenes sobre las precauciones que deben tener ante las "tentaciones", cuando los adultos y las personas casadas también cometen faltas relacionadas al adulterio o al consumo de pornografía por ejemplo.

Observando y analizando en detalle pueden reconocerse sutiles desplazamientos entre lo normado y las propias interpretaciones que realizan los jóvenes de ello, para poder reconocer la heterogeneidad de formas en que se habita el cuerpo como territorio en clave juvenil, en el cruce entre lo normado sus deseos sus prácticas y experiencias.

\section{Conclusiones}

Para presentar las conclusiones de este trabajo vale recordar la propuesta presentada en el inicio del mismo referida a la idea de abordar la relación entre corporalidad y creencias, con la intención de observar y analizar diferentes prácticas sobre el cuerpo que, en su conjunto, permitan comprender distintos aspectos sobre las visiones y experiencias en torno a la corporalidad en el marco del evangelismo pentecostal. Así, el punto de partida de este recorrido fue presentar distintos autores de referencia en el campo de las ciencias sociales que aportan categorías, conceptos y formas de abordar las corporalidades, factibles de ser incorporados al análisis propuesto sobre los cuerpos juveniles evangélicos como territorios.

En el caso específico del enfoque propuesto, encuentro una complementariedad entre las dos grandes corrientes del pensamiento social que se centraron en el cuerpo: mientras que el posestructuralismo ofrece el potencial para comprender el cuerpo como un objeto socialmente constituido, eje de discursos y representaciones; desde la fenomenología podemos comprender las creencias como experiencias corpóreas. En este sentido es que desarrollo la idea del cuerpo territorio de creencias, pensando al cuerpo juvenil como una construcción social cruzada por discursos, normas, prácticas y disputas de sentido, a la vez que es el cuerpo el territorio donde la creencia se asienta, se produce y exterioriza. Sostengo entonces que la idea de cuerpo como templo engloba una relación con el cuerpo, que da lugar a toda una serie de discursos sobre los cuidados que se deben implementar y, a la vez, también se relaciona con la concepción subjetiva del cuerpo como templo del Espíritu Santo, vinculadas a las experiencias religiosas que se vivencian. 
Como forma de resumir lo desarrollado, destaco que en relación a los cuerpos juveniles como territorios de creencia que generan sentido, activan, transforman y reproducen, es posible reconocer tensiones de varios tipos: entre la reproducción y la agencia, entre la disciplina y el empoderamiento y entre la normalización y la personalización. Sobre estas bases, en mi enfoque priorizo atender a las prácticas para pensar desde allí cómo se estaban produciendo y articulando sentidos sobre el cuerpo juvenil como territorio. Respecto a las formas en que se observan tensiones entre la reproducción religiosa y la agencia juvenil en lo referido a las formas de vivir y experimentar sus creencias religiosas, encuentro que los jóvenes si bien practican ciertos mandatos también disputan sutilmente normas y sentidos sobre las regulaciones de los cuerpos juveniles.

A lo largo del desarrollo del trabajo fue posible reconocer cómo emerge la concepción adulta sobre la juventud, según la cual se piensa a lo juvenil como etapa liminar que requiere de una atención especial sobre todo desde las normas morales. Esto implica el pensar a las y los jóvenes como seres incompletos, que van camino a ser, y por ello la necesidad de encauzarlos, sobre todo a partir del desarrollo de actividades donde subliman sus energías y las vuelquen al trabajo pastoral, presentándose así como uno de los vectores que aporten al crecimiento de sus comunidades religiosas. Además, se considera que los jóvenes son seres de especial cuidado por las posibilidades de desviarse, debido a las características que se les atribuye en este ciclo vital ligadas al desborde pasional, siempre desde una perspectiva adultocéntrica.

Igualmente, como mencioné antes, la agencia juvenil no sólo se expresa desde la subversión a las normas, sino también en las formas en que son vividas y experimentadas. Entonces, también la agencia juvenil puede observarse en las formas en que se acatan ciertas normas, por ejemplo, en la decisión de mantenerse en castidad expresado en los relatos presentados, o en participar de un espacio de formación intensivo, practicando el ayuno religioso como forma de aprender el dominio del propio cuerpo. Dentro de la gestión de la corporalidad, los jóvenes en estos contextos incorporan las tecnologías del yo, según las cuales son llamados a establecer un intenso cuidado de sí mismos con el fin de corregirse y explorarse en sus conductas, para que cuando cometan faltas deban confesarse ante otro superior para que los oriente y castigue. En este aspecto, es donde emergen claramente los contrastes y diferencias entre los jóvenes que deciden acatar la norma y los que sutilmente plantean que la castidad no representa un valor en sí, sino que estas prohibiciones son vistas como normas tradicionales pero de difícil cumplimiento en los contextos actuales.

Por último, resulta un desafío en los estudios de la corporalidad intentar superar la perspectiva representacional para poder captar otro tipo de saber, el corporal, que en relación al interés por 
indagar las formas en que la creencia se expresa, conduce a comprender que la creencia existe en el cuerpo, es decir no se expresa a través de, sino que existe encarnadamente.

\section{Notas}

(1) Véase Citro (2009; 2011 y 2012).

(2) Al respecto plantea Segato: "La sanción sobre el cuerpo de la mujer es un lugar privilegiado para significar el dominio y la potencia cohesiva de la colectividad, y prácticas de larguísima duración histórica confirman esta función de la capacidad normativa (y hasta predadora) sobre el cuerpo femenino como índice de la unión y fuerza de una sociedad. La significación territorial de la corporalidad femenina -equivalencia y continuidad semántica entre cuerpo de mujer y territorio- es el fundamento cognitivo de estas prácticas" (2008: 53).

\section{Bibliografía}

Bourdieu, P. (1986). Notas provisionales sobre la percepción social del cuerpo. En AA. VV. Materiales de sociología crítica (pp. 183-194). Madrid: La Piqueta.

Bourdieu, P. (2007). El sentido práctico. Madrid: Taurus.

Butler, J. (2002). Cuerpos que importan. Sobre los límites materiales y discursivos del sexo. Buenos Aires: Paidós.

Carballo, C. (2012). La corporalidad como nuevos territorios de espacialidad religiosa. Espaço e Cultura, UERJ, 32, pp. 61-78.

Citro, S. (2011). Cuerpos plurales. Antropología de y desde los cuerpos. Buenos Aires: Editorial Biblos.

Citro, S. (2009). Cuerpos significantes. Travesías de una etnografía dialéctica. Buenos Aires: Editorial Biblos.

Citro, S. (2004). La construcción de una antropología del cuerpo: propuestas para un abordaje dialéctico. Anales del VII Congreso Argentino de Antropología Social, Simposio: propuestas para una antropología del cuerpo. Villa Giardino, Córdoba, s/d.

De Certau, M. (1996). La invención de lo cotidiano. El arte de hacer (1르 ed., Tomo I). México: Universidad Iberoamericana.

Douglas, M. (1991). Pureza y peligro. Un análisis de los conceptos de contaminación y tabú. Madrid: Siglo XXI. 
Douglas, M. (1988). Símbolos Naturales. Exploraciones en cosmología. Madrid: Alianza Editorial.

Elias, N. (1993). El proceso de la Civilización. Investigaciones sociogenéticas y psicogenéticas. Buenos Aires: Fondo de Cultura Económica.

Foucault, M. (1991). Tecnologías del yo y otros escritos afines. Barcelona: Paidós.

Foucault, M. (1992). Microfísica del poder. Madrid: La Piqueta.

Foucault, M. (1997). Vigilar y castigar. México: Siglo XXI.

Foucault, M. (2003). Historia de la sexualidad. La voluntad del saber (Tomo I). México: Siglo $\mathrm{XXI}$.

Foucault, M. (2008). Los anormales. Buenos Aires: Fondo de Cultura Económica.

Mosqueira, M. (2014). Santa rebeldía. Construcciones de juventud en comunidades pentecostales del Área Metropolitana de Buenos Aires (Tesis de Doctorado). Facultad de Ciencias Sociales, Universidad de Buenos Aires, Buenos Aires.

Mahmood, S. (2006). Teoría feminista, agência e sujeito liberatório: algumas reflexões sobre o revivalismo islâmico no Egipto. Etnográfica, 10, pp. 121-158.

Marx, K. (1976). Manuscritos económico- filosóficos de 1884. México: Cultura Popular.

Mauss, M. (1979). Sociología y antropología. Madrid: Editorial Tecnos.

Rabelo, M. (2014). A articula cao de corpos e espacos no candomble. En Oro, A. y Tadvald, M. (comp.). Circuitos religiosos: Pluralidade e interculturalidade (pp. 235-253). Porto Alegre: Cirkula.

Segato, R. (2013). Territorio, soberanía y crímenes de segundo estado. La escritura en el cuerpo de las mujeres asesinadas en Ciudad Juárez. Buenos Aires: Editorial Tinta Limón. 